Journal of Scientific Perspectives

Volume 3, Issue 3, Year 2019, pp. 207-214

E - ISSN: 2587-3008

URL: http://ratingacademy.com.tr/ojs/index.php/jsp

DOİ: https://doi.org/10.26900/jsp.3.021

Research Article

\title{
EFFECT OF DIFFERENT THICKNESS AND SOLUTION CONCENTRATION ON CUS THIN FILM GROWN BY SILAR METHOD
}

\author{
Tuba ÇAYIR TAŞDEMIRCI* \\ * Dr., Erzincan Binali Yıldırtm University, Department of Biomedical Engineering, TURKEY \\ e-mail: tcayir@erzincan.edu.tr
}

ORCID ID: https://orcid.org/0000-0001-9519-8483

Received: 7 July 2019; Accepted: 26 July 2019

\begin{abstract}
In this study, CuS thin films were successfully coated on glass substrate at room temperature using successive ionic layer absorption and reaction (SILAR) method. Thickness and solution concentration parameters which are important in SILAR management were used to obtain CuS thin films. X-Ray diffraction spectroscopy (XRD), Scanning Electron Microscopy (SEM) / Energy SpreadXray Spectroscopy (EDX) were used to examine the changes in thickness and solution concentration in the structure of $\mathrm{CuS}$ thin films. Because of the investigations, it was found that $\mathrm{CuS}$ thin films improved both the number of cycles and the concentration of the solution and that the crystal structure improved and the SEM / EDX results supported this result.
\end{abstract}

Keywords: CuS, SILAR, deposition, thin film. 


\section{INTRODUCTION}

Copper sulfide $\left(\mathrm{Cu}_{\mathrm{x}} \mathrm{S}\right)$ is a p-type semiconductor with five different stable phases at room temperature, namely, chalcocite $\left(\mathrm{Cu}_{2} \mathrm{~S}\right)$, djurleite $\left(\mathrm{Cu}_{1.96} \mathrm{~S}\right)$, digenite $\left(\mathrm{Cu}_{1.85} \mathrm{~S}\right)$, anilite $\left(\mathrm{Cu}_{1.75} \mathrm{~S}\right)$ and covellite $(\mathrm{CuS})$. Depending on the stoichiometric composition, the $\mathrm{Cu}_{\mathrm{x}} \mathrm{S}$ band gap may vary between 1.2 and $2.53 \mathrm{eV}$ by Grozdanov and Naidaski in[1], Bagul et al in [2]. Moreover, this semiconductor has metal-like electrical conductivity because copper vacancies act as acceptors by Cruz-Vazquez et al in [3]. CuS thin films, electronics, optics and chemical properties are among the most important semiconductors by Chen et al in [4]. CuS thin films are widely used in many areas. We can list these fields as solar electrodes, radiation filters, organic polymers and coatings as electro-conductors. In addition to its excellent optoelectronic properties, $\mathrm{CuS}$ is abundant in the earth's crust, which is not dangerous, economical and environmentally friendly. Photosensors have tremendous applications in a wide range of electronic devices, circuits and systems. This proves its importance in a wide range of applications such as new generation displays, touch screens, fiber optic systems, optical scanners, automatic lighting controls and remote-control devices.

$\mathrm{CuS}$ thin films, which can be used in many areas, were grown using many chemical methods. These chemical methods include chemical vapor deposition by Gorai et al in [5], successive ionic layer adsorption and reaction (SILAR) method Güzeldir et al in [6], chemical bath deposition (CBD) by Kemmler et al in [7], spray pyrolysis by Sagade ve Sharma in [8]. Among these methods, SILAR method, low cost, PH, solution concentration, easy to parameters such as coating cycle

Controlled, thin film coating can also be done without distinguishing the surface type and shape. In this study, CuS thin films were grown on glass substrates using different solution concentrations and different thicknesses by SILAR method. The effect of XRD, SEM / EDX analysis, thickness and solution concentration of four different thin films on the crystal structure of the formed film was investigated on the surface.

\section{MATERIAL AND METHOD}

SILAR method is a very useful method for obtaining thin film according to many chemical growth methods. In SILAR method, thin film amplification is realized by changing parameters such as solution molarity, $\mathrm{pH}$ value, thickness and temperature. Each parameter can provide different convenience. Two solutions were prepared to obtain $\mathrm{CuS}$ by considering these conditions. $\mathrm{CuCl}_{2}(\mathrm{pH}=3)$ was used as the source of $\mathrm{Cu}$ and $\mathrm{Na}_{2} \mathrm{~S}(\mathrm{pH}=12)$ solution was prepared as the $\mathrm{S}$ source. $0.1 \mathrm{M} \mathrm{CuCl}_{2}$ solution, $0.1 \mathrm{M} \mathrm{Na}_{2} \mathrm{~S}$ solution was used to coating the $\mathrm{CuS}$ thin film. Likewise, copper chloride and sodium sulfide solutions were prepared in different molarity $\left(0.2 \mathrm{M} \mathrm{CuCl}_{2} \quad 0.2 \mathrm{M} \mathrm{Na} \mathrm{S}_{2} \mathrm{~S}\right.$ solution). Microscope glass coverslips were prepared by taking $10 \times 10 \times 2 \mathrm{~mm}^{3}$ size sections as a film to be thin film coated. The glass mats have passed the cleaning step before coating. It was first cleaned in dilute sulfuric acid solution with acetone and then made ready for coating by passing through pure water.

The SILAR method consists of four stages. In the first stage, the glass substrate is immersed in the solution for 20 seconds by immersing the glass substrate in a solution, so that the $\mathrm{Cu}^{+2}$ and $\mathrm{Cl}^{-2}$ ions adhere to the glass base. In the second step, the glass substrate is immersed in deionized water for 10 seconds to remove the weakly bonded $\mathrm{Cl}^{-2}$ ions on the substrate. In the third stage, the glass bottom of the $\mathrm{Na}_{2} \mathrm{~S}$ solution narrows for 20 seconds, and the $\mathrm{Na}^{+2}$ and $\mathrm{S}^{-2}$ ions adhere to the surface. In the fourth step, the weakly bound $\mathrm{S}^{-2}$ ions are immersed in deionized water for 10 seconds to leave the surface. Thus, a SILAR cycle is completed. Figure 1 shows a schematic representation of the SILAR method. 
Figure 1. Schematic representation of SILAR method.
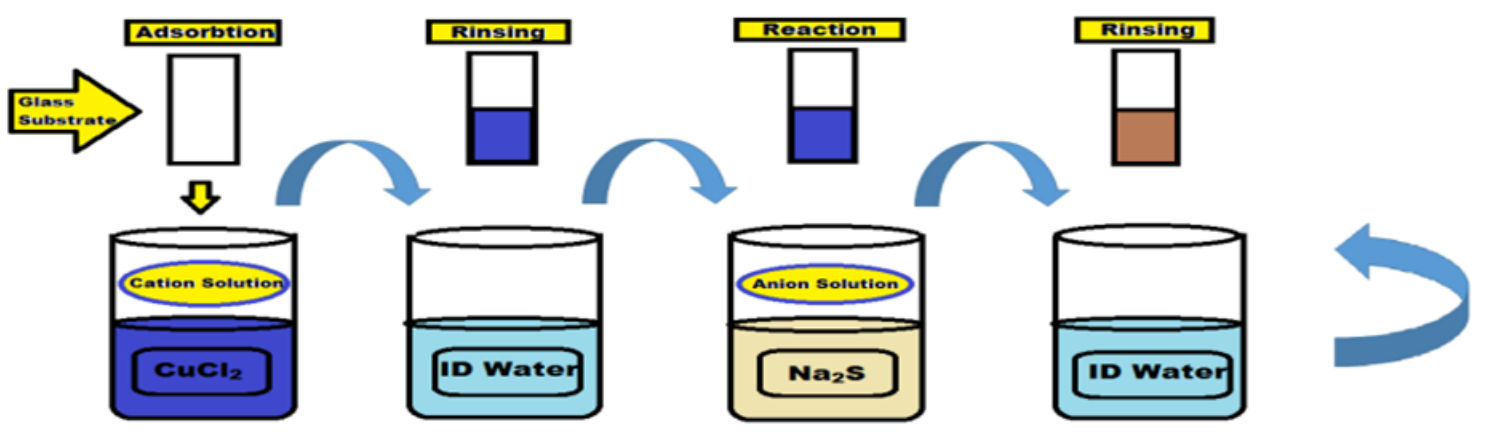

This process continues until the surface is homogeneously coated. CuS thin films are homogeneously coated after 30 SILAR cycles. CuS thin films were coated in different sizes in 30 and 40 cycles. Table 1 shows the parameters used to grow $\mathrm{CuS}$ thin film.

Table 1. Optimized deposition parameters for $\mathrm{CuS}$ thin film

\begin{tabular}{|l|c|c|}
\hline \multicolumn{1}{|c|}{ Deposition Parameters } & Cationic Precursor & Anionic Precursor \\
\hline Precursor & $\mathrm{CuCl}_{2}$ & $\mathrm{Na}_{2} \mathrm{~S}$ \\
\hline Concentration $(\mathrm{M})$ & $0.1 / 0.2$ & $0.1 / 0.2$ \\
\hline $\mathrm{pH}$ & 3 & 12 \\
\hline Immersion Time(s) & 20 & 20 \\
\hline Rinsing Time (s) & 10 & 10 \\
\hline Volume of Precursor $(\mathrm{mL})$ & 100 & 100 \\
\hline SILAR Cycle & $30 / 40$ & $30 / 40$ \\
\hline
\end{tabular}

XRD and SEM/EDX devices were used for the structural analysis of CuS thin films coated in 0.1 and $0.2 \mathrm{M}$ solution and different cycle. The brands and models of XRD and SEM/EDX used for the analysis of CuS thin films are, respectively, Rigaku 2200D / Max, XRay Diffractometer, Zeiss Supra and Perkin-Elmer.

\section{RESULTS}

Figure 2 shows the XRD patterns of $\mathrm{CuS}$ thin films. XRD diffraction peaks were taken between $20^{\circ}-60^{\circ}(2 \theta)$. When the CuS thin film ( 30 cycle) was enlarged to $0.1 \mathrm{M}$, the $2 \theta$ angle showed a peak at 31.682 and 48.050 , while the $0.2 \mathrm{M} \mathrm{CuS}$ thin film showed peaks at 21.618, 29.110 and 42.922 in addition to these peaks. According to JCPDS-06-0464, the orientations of the peaks in these angles were obtained as $21.618,29.110,31.682,42.922$ and $48.050(00$ 4), ( $\left.\begin{array}{lll}0 & 1 & 2\end{array}\right),\left(\begin{array}{lll}0 & 1 & 3\end{array}\right),\left(\begin{array}{lll}0 & 1 & 6\end{array}\right)$ and ( $\left.\begin{array}{lll}1 & 1 & 0\end{array}\right)$, respectively. When the CuS thin film (40 cycle) was enlarged to $0.1 \mathrm{M}$, the $2 \theta$ angle showed a peak at $29.110,31.682$ and 47.808 , while the $0.2 \mathrm{M}$ $\mathrm{CuS}$ thin film showed peaks at 21.618 and 42.922 in addition to these peaks. According to JCPDS-06-0464, the orientations of the peaks in these angles were obtained as 21.618, 29.110, 31.682, 42.922 and 47.808 (0 $\left.0 \begin{array}{lll}0 & 4\end{array}\right),\left(\begin{array}{lll}0 & 1 & 2\end{array}\right),\left(\begin{array}{lll}0 & 1 & 3\end{array}\right),\left(\begin{array}{lll}0 & 1 & 6\end{array}\right)$ and (1 110$)$, respectively. These planes indicated hexagonal crystal structure for $\mathrm{CuS}$ thin film. $\mathrm{CuS}$ shows that thin films have a polycrystalline structure with orientation along different planes. I can say that the crystal structure improved by increasing the precursor molarity and number of cycles. 
Figure 2. XRD patterns of $\mathrm{CuS}$ thin films grown at 30 and 40 cycles.
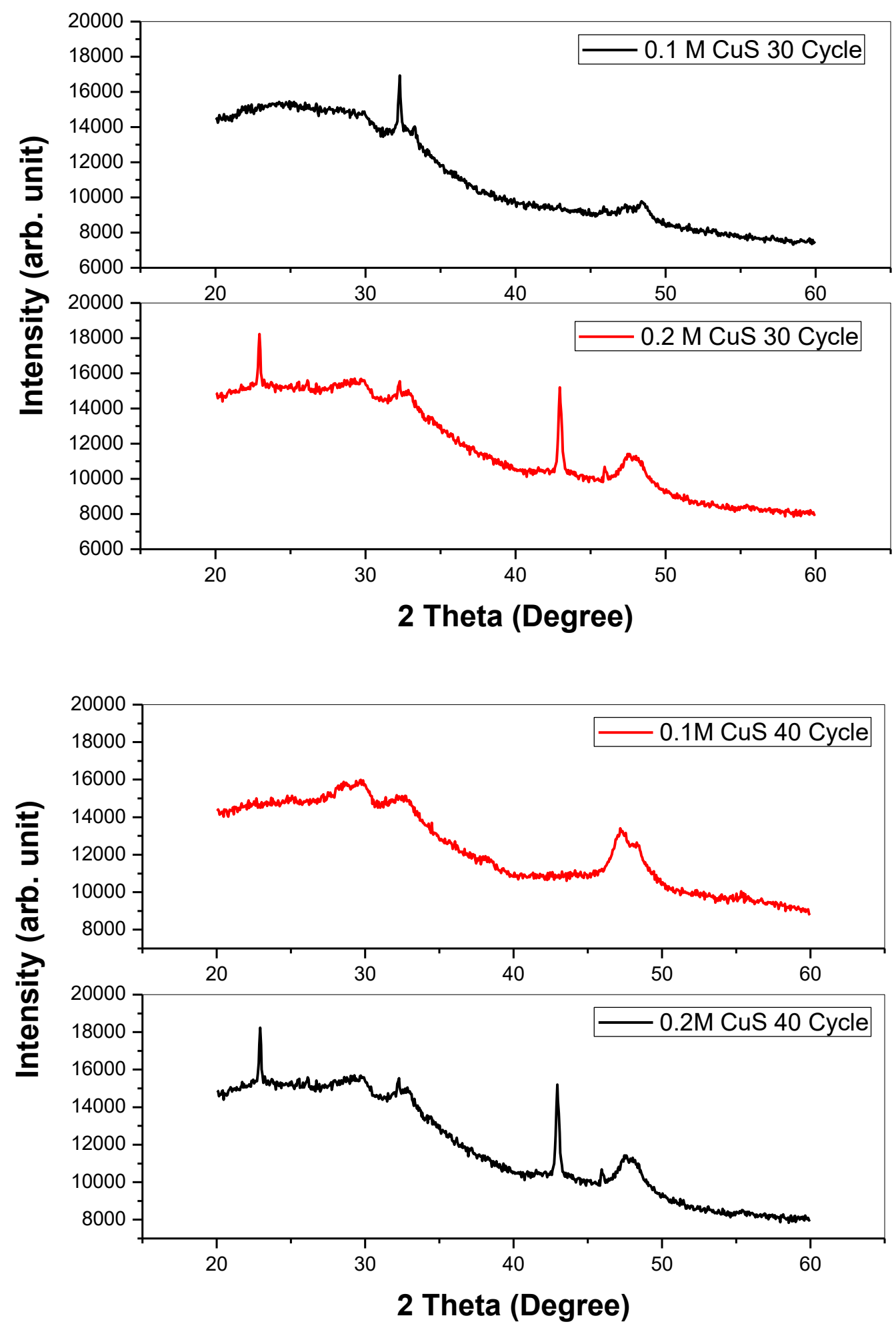

Figure 3 and 4 shows the SEM results of $0.1 \mathrm{M}$ and $0.2 \mathrm{M} \mathrm{CuS}$ thin films growth 30 and 40 cycles at 100,000 magnifications. In the measurements made using scanning electron microscope, I can say that the $\mathrm{CuS}$ thin film is coated on the surface homogeneously. It is seen that well-crystallized grains in the first image belong to $\mathrm{CuS}$ film. The $\mathrm{CuS}$ film is dense, 
uniform and homogeneous without visible pores and covered well with glass substrate. $\mathrm{CuS}$ film is rough due to the formation of big grains.

Figure 3. SEM images of 100.000x magnifications of $0.1 \mathrm{M}$ and $0.2 \mathrm{M} \mathrm{CuS}$ thin films grown at 30 cycles.
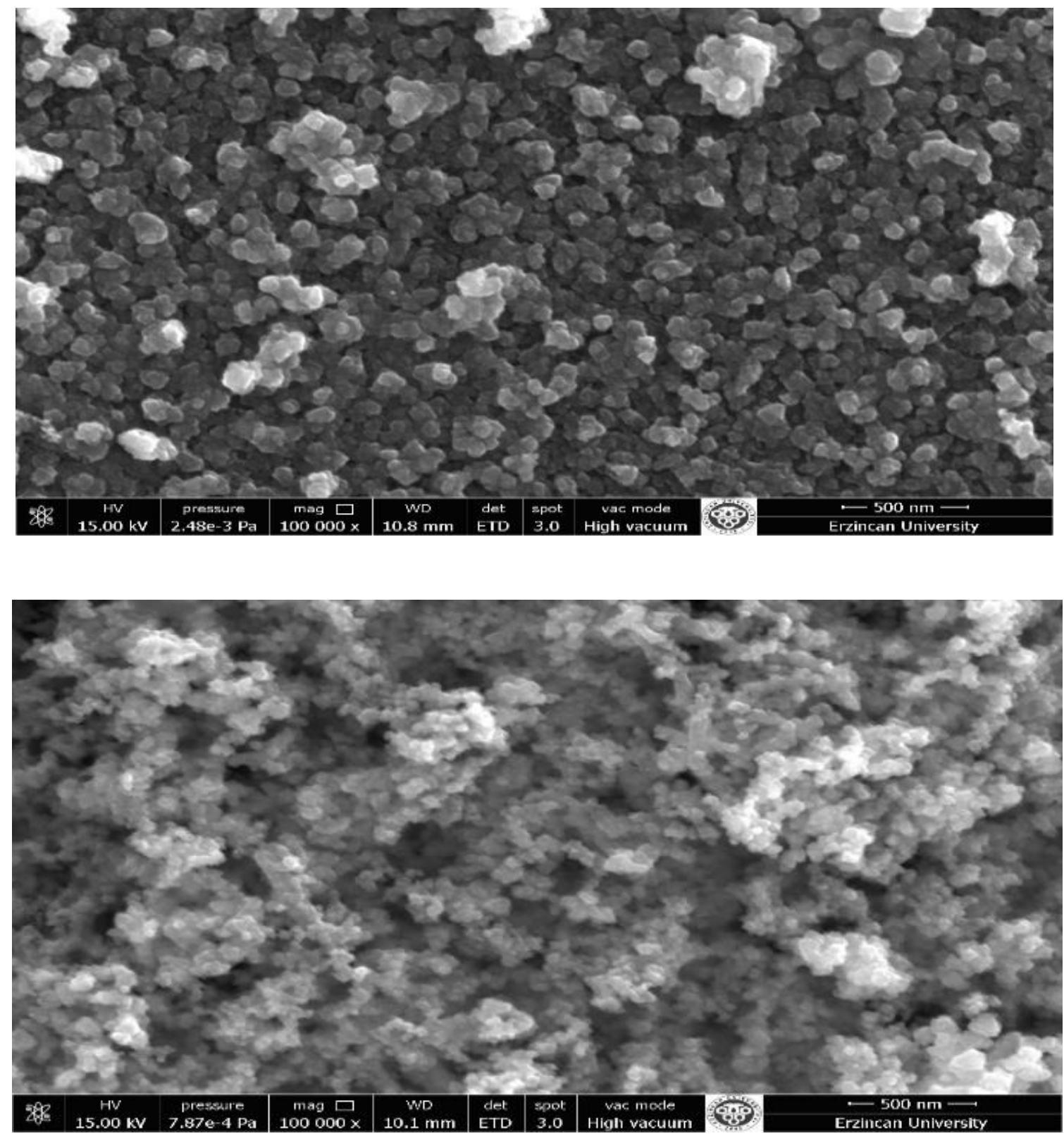

It was determined that the thin films obtained due to the increase in precursor moles had more deposition on the surfaces. In other words, it was found that there was more CuS structure on the surface of the thin film coated with $0.2 \mathrm{M}$ than the $0.1 \mathrm{M}$ solution. The increase in solution concentration resulted in a more compact coating of the surface structure. Different $\mathrm{CuS}$ thin films were obtained by applying 40 SILAR cycles by increasing the number of cycles of $\mathrm{CuS}$ thin films made using 30 SILAR cycles. 
Figure 4. SEM images of 100.000x magnifications of $0.1 \mathrm{M}$ and $0.2 \mathrm{M} \mathrm{CuS}$ thin films grown at 40 cycles.
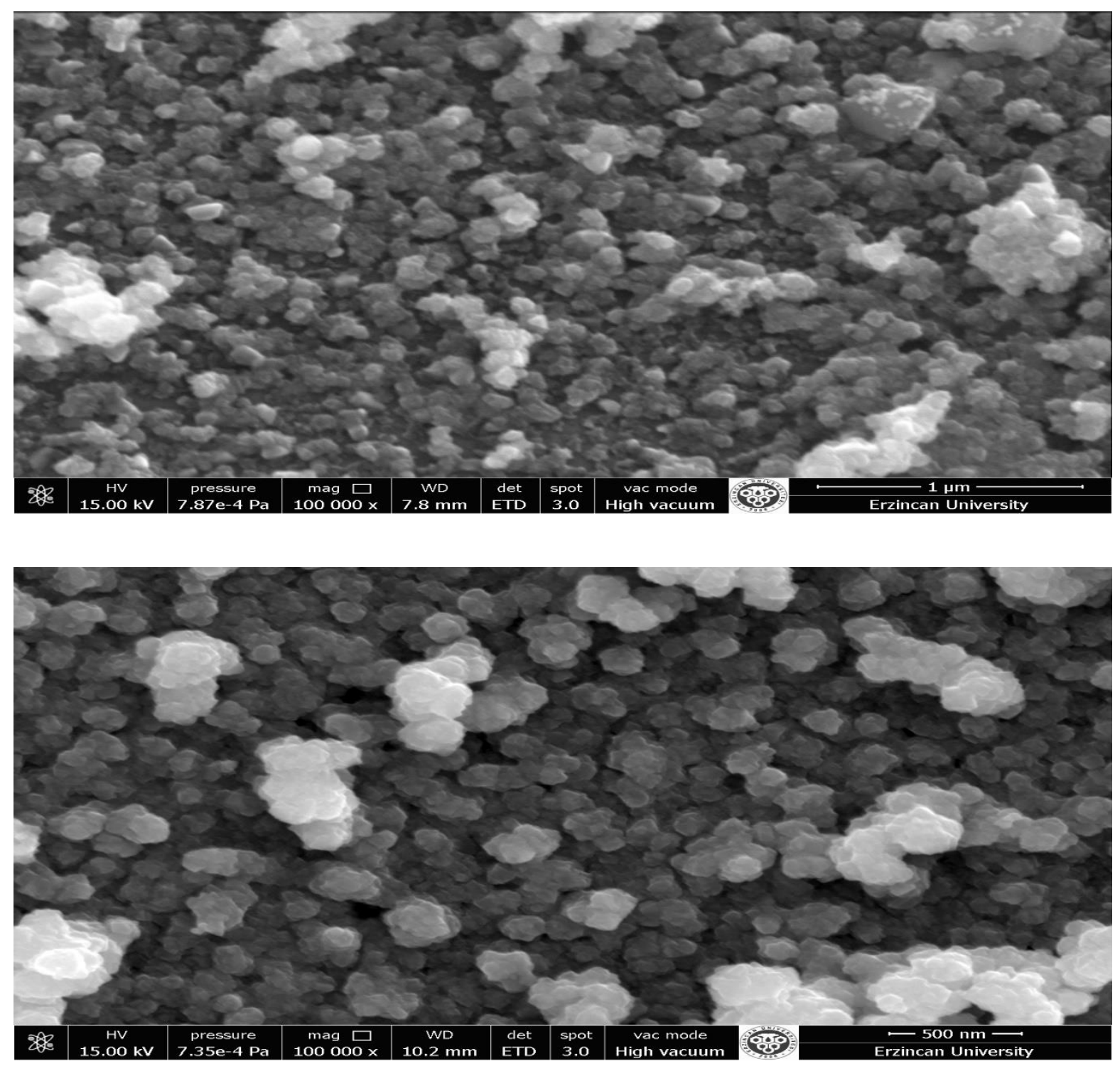

Increasing both the solution concentration and the number of cycles of $\mathrm{CuS}$ thin films had a positive effect on the results. Figure 5 shows the EDX results of CuS thin films. The EDX determines the elemental distribution on the surface of $\mathrm{CuS}$ thin films. The $\mathrm{Cu}$ and $\mathrm{S}$ ratio increased from 48.19 to 75.74 and 17 to 24.26 , respectively, by coating the $\mathrm{CuS}$ thin films grown at 30 cycles in $0.1 \mathrm{M}$ and $0.2 \mathrm{M}$ solution, respectively. 
Figure 5. EDX images of $0.1 \mathrm{M}$ and $0.2 \mathrm{M} \mathrm{CuS}$ thin films grown at 30 and 40 cycles.
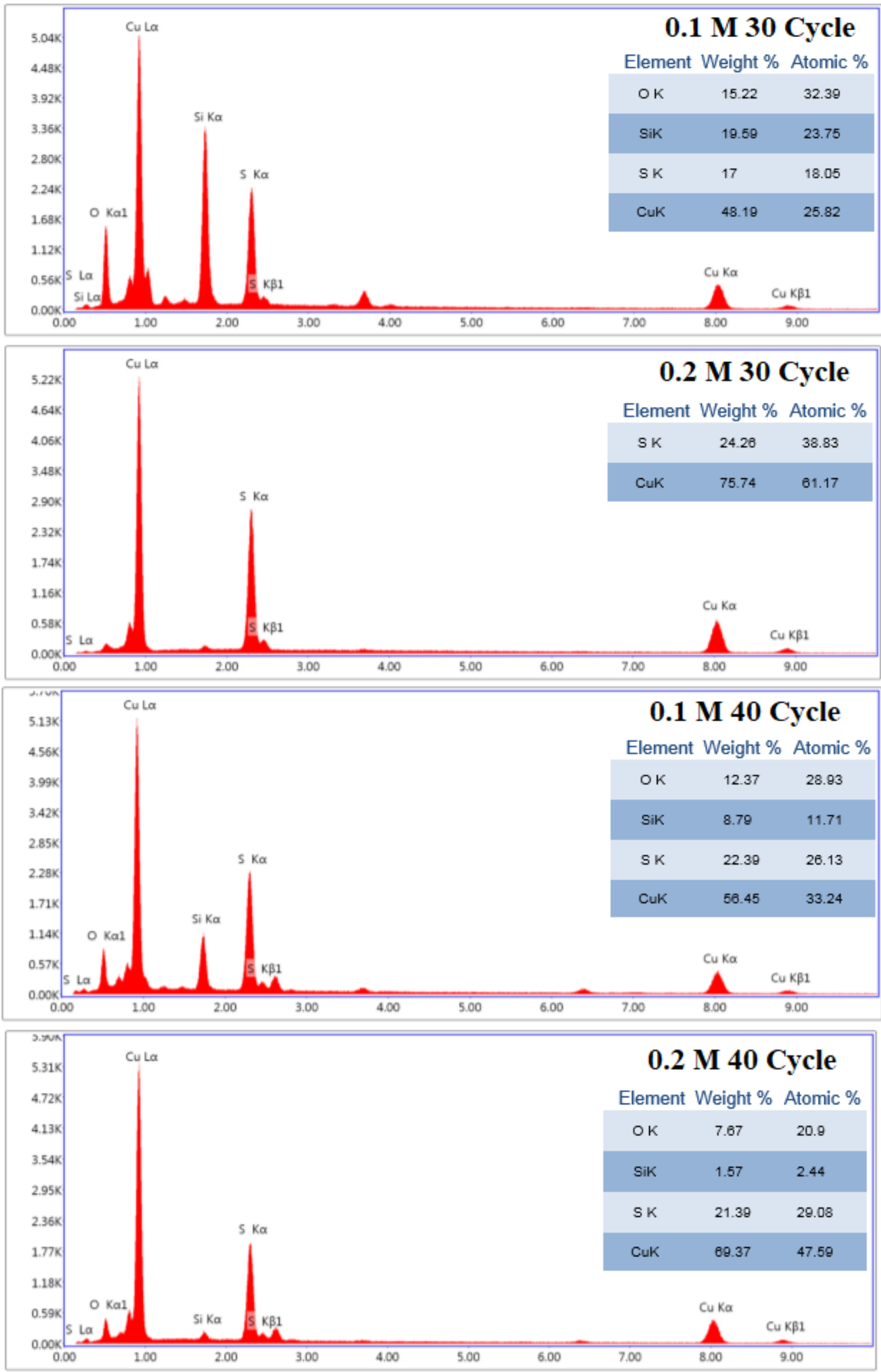
The increase in solution concentration resulted in a more compact coating of the surface. Likewise, $\mathrm{CuS}$ thin films grown at 40 cycles are the same. The ratio of $\mathrm{Cu}$ and $\mathrm{S}$ shows an increase in surface dispersion depending on the concentration of the solution. Considering the number of cycles, the elemental ratio of $\mathrm{CuS}$ thin films grown at 30 and 40 cycles from $0.1 \mathrm{M}$ increased from 48.19 to 56.45 for $\mathrm{Cu}$ and from 17 to 22.39 for $\mathrm{S}$ element. At a solution concentration of $0.2 \mathrm{M}$, this is the exact opposite. $\mathrm{Cu}$ and $\mathrm{S}$ ratio decreased with increasing number of cycles. This may be due to the inability to maintain the sample very well.

\section{CONCLUSION}

In this study, $\mathrm{CuS}$ thin films were coated on glass surface at different room temperature using SILAR method in different molarities and number of cycles. The structural properties of the $\mathrm{CuS}$ thin films were investigated according to the molarity and number of cycles. Thin-film enlargement processes can be used to temperature, thickness, etc. parameters were taken into consideration. This study revealed that we could obtain more homogenous and more crystalline films in a shorter time by increasing the molarity and number of cycles (thickness) in CuS thin film. We can say that SILAR method is a suitable method to enlarge the thin film of CuS.

\section{REFERENCES}

[1] I. Grozdanov, M. Najdoski, 1995, Optical and electrical properties of copper sulfide films of variable composition, J. Solid State Chem. 114, 469-475.

[2] S.V. Bagul, S.D. Chavhan, Ramphal Sharma, 2007, Growth and characterization of $\mathrm{Cu}_{\mathrm{x}} \mathrm{S}(\mathrm{x}=1.0,1.76$, and 2.0) thin films grown by solution growth technique (SGT), J.Phys. Chem. Solids 68, 1623-1629.

[3] C. Cruz-Vázquez, M. Inoue, M.B. Inoue, R. Bernal, F.J. Espinoza-Beltrán, 2000, Electrical and spectroscopic properties of amorphous copper sulfide films treated with iodine, lithium iodide and sodium iodide, Thin Solid Films 373, 1-5.

[4] Y. Chen, C. Davoisne, J.M. Tarascon, C. Guery, 2012, Growth of single-crystal copper sulfide thin films via electrodeposition in ionic liquid media for lithium ion batteries, Journal of Material Chemistry $22,5295-5299$.

[5] S. Gorai, D. Ganguli, S. Chaudhuri,2005, Shape selective solvothermal synthesis of copper sulphides: role of ethylenediamine-water solvent system, Materials Science and Engineering: B 116, 221-225.

[6] B. Güzeldir, M. Sağlam, A. Ateş, 2012, Deposition and Characterization of CdS, CuS and ZnS Thin Films Deposited by SILAR Method, Acta Physica Polonica A. 121, 33-35.

[7] M. Kemmler, M. Lazell, P. O’Brien, D.J. Otway, J.H. Park, J.R. Walsh, 2002, The growth of thin films of copper chalcogenide films by MOCVD and AACVD using novel singlemolecule precursors, Journal Material Science 13, 531-535.

[8] A.A. Sagade, R. Sharma, 2008, Copper sulphide $\left(\mathrm{Cu}_{\mathrm{x}} \mathrm{S}\right)$ as an ammonia gas sensor working at room temperature, Sensors and Actuators B 133, 135-143. 